pp. $689-707$

\title{
FDTD Simulations and Measurements for Cell Phone with Planar Antennas
}

\author{
Claudio R. FERNÁNDEZ*, Mateus BONADIMAN**, Alvaro. A. A. DE SALLES*
}

\begin{abstract}
The Finite-Difference Time-Domain (FDTD) method is used to calculate the cellular phone far and near field and the specific absorption rate (SAR) in the user's head. The conventional 入/4 monopole and a simple planar antenna are simulated and measured. The simulated results are in good agreement with those measured for the VSWR and for the radiation patterns on the horizontal and vertical planes. These results show that significant improvements in the antenna radiation efficiency and in the reduction of the SAR in the head are obtained when planar antennas are used.
\end{abstract}

Key words: Finite-Difference Time-Domain (FDTD), Specific Absorption Rate (SAR), Cellular Phone, Biological Effects, Planar Antennas.

\section{TITRE FRANCAIS}

\section{Résumé}

On utilise la méthode des Différences Finies dans le Domaine Temps (FDTD) pour calculer les champs électriques dans la région proche et éloignée, que le téléphone cellulaire irradie, et le Taux d'Absorption Spécifique (SAR) dans la tête de l'utilisateur. On simule et on mesure le monopole conventionnel de $\mathrm{N} 4$ et une simple antenne planaire. Les résultats simulés concordent avec les résultats mesurés du Taux d'Onde Stationnaire (VSWR) et des diagrammes de rayonnement sur le plan horizontal et sur le plan vertical. Ces résultats montrent qu'en utilisant des antennes planaires, on améliore significativement l'efficacité de rayonnement de l'antenne et la réduction du SAR dans la tête.

Mots clés :

\footnotetext{
* Electrical Engineering Department, Federal University of Rio Grande do Sul (UFRGS), Porto Alegre, RS 90035190, Brasil (phone: ++55-51-3316-3517; fax: ++55-51-3316-3293; e-mail: aasalles@vortex.ufrgs.br, fdez@iee.ufrgs.br).

** was with the E.E.Dept. UfRGS. He is now with the Electrical Engineering Department, Aeronautical Technologic Institute (ITA), São José dos Campos, SP, Brasil (e-mail: mbonad@ele.ita.br).

The authors are with the Optoelectronic Communications Laboratory, Electrical Engineering Department, UFRGS, Av. Osvaldo Aranha, 103, Porto Alegre, 90.035-190, RS, Brazil, Tel. + 55-51-33163517, Fax. + 55-51-33163293. M. Bonadiman, mbonad@iee.ufrgs.br; C. Fernández, fdez@iee.ufrgs.br and A. A. de Salles, aasalles@vortex.ufrgs.br.
} 


\section{Contents}

\author{
I. Introduction \\ II. Modelling \\ III. Measured results
}

\author{
IV. Comments and conclusions \\ References (36 ref.)
}

\section{INTRODUCTION}

The monopole (or whip) antennas are now widely used in mobile phones. Their radiation pattern on the horizontal plane is nearly symmetrical around them. Then, in the usual situation of operation, when these antennas are placed very close to the head, most of the radiated energy is absorbed in the user's head (e.g., in the brain tissues, in the eyes, etc.) and a smaller portion of energy is radiated to the nearest base station. This is an undesired situation, since there is a degradation on the communication's quality and the user's health risk is increased.

The use of planar antennas with moderate directivity for mobile phones has been suggested by several authors [1]-[5]. These antennas radiate more in the direction opposed to the head, improving the quality of communication, reducing the battery drain and the user's health risks. They can have small dimensions and a compact form, integrated to the cell phone box. Also, they can be very low cost, resulting therefore in an interesting alternative for this application.

The design, performance simulation and relevant measured results for a $1.9 \mathrm{GHz}$ rectangular microstrip (patch) antenna using low loss substrate, together with its benefits when used in mobile phones are presented and discussed in this work.

\section{MODELLING}

Near field and far field simulations of the patch antenna, as well as of the conventional monopole antenna were performed using algorithms based on the FDTD method, developed in $\mathrm{C}++$ and with a mesh representing the user's head built from neuro-anatomical data. The simulations were processed in the CRAY T94 parallel supercomputer [6].

The FDTD method provides a full wave solution of Maxwell's equations,

$$
\begin{aligned}
& \nabla \times \vec{H}=\varepsilon \cdot \frac{\partial \vec{E}}{\partial t}+\sigma \cdot E \\
& \nabla \times \vec{E}=\mu \cdot \frac{\partial \vec{H}}{\partial t}+p \cdot \vec{H}
\end{aligned}
$$

where $\sigma$ is the conductivity, $\varepsilon$ is the permittivity (dielectric constant), $\mu$ is the permeability and $\rho^{*}$ is an equivalent magnetic resistivity. These are discretized and transformed in finite difference explicit equations, such as [7] 


$$
\begin{aligned}
\frac{\partial H_{x}}{\partial t}= & \frac{1}{\mu}\left(\frac{\partial E_{y}}{\partial z}-\frac{\partial E_{z}}{\partial y}-p^{\bullet} H_{x}\right) \Rightarrow \frac{H_{x i, j, k}^{n+1 / 2}-H_{x i, j, k}^{n-1 / 2}}{\Delta t}= \\
\quad & \frac{1}{\mu_{j, k}}=\times\left(\frac{E_{y_{i, j, k+1 / 2}^{n}}^{n}-E_{y_{i, j, k-1 / 2}}^{n}}{\Delta z}-\frac{E_{z_{i, j+1 / 2, k}^{n}}^{n}-E_{z_{i, j-1 / 2, k}}^{n}}{\Delta y}-p_{i, j, k}^{\bullet} H_{x i, j, k}^{n}\right),
\end{aligned}
$$

where $i, j$ and $k$ are indicate the position in the mesh where the values should be calculated and $n$ is the iteration number (related to time).

These are adapted in order to save memory as

$$
\begin{aligned}
E x_{i, j, k}^{n+1}= & \left(\frac{1-\frac{\sigma_{i, j, k} \cdot \Delta t}{2 \cdot \varepsilon_{i, j, k}}}{1+\frac{\sigma_{i, j, k} \cdot \Delta t}{2 \cdot \varepsilon_{i, j, k}}}\right) \times E x_{i, j, k}^{n}+\left(\frac{\frac{\Delta t}{\varepsilon_{i, j, k}}}{1+\frac{\sigma_{i, j, k} \cdot \Delta t}{2 \cdot \varepsilon_{i, j, k}}}\right) \times \\
& \left(\frac{H z_{i, j, k}^{n+1}-H z_{i, j,-1, k}^{n+1}}{\Delta y}-\frac{H y_{i, j, k}^{n+1}-H y_{i, j, k,-1}^{n+1}}{\Delta z}\right),
\end{aligned}
$$

and solved in an iterative form.

Boundary conditions, source implementation, initial conditions and stability must be considered [7]. Particularly the "Magic step" (Courant condition)

$$
\Delta t \leq \frac{1}{c \cdot \sqrt{\left(\frac{1}{\Delta x}\right)^{2}+\left(\frac{1}{\Delta y}\right)^{2}+\left(\frac{1}{\Delta z}\right)^{2}}}
$$

was used. In order to verify the numerical dispersion, the near field simulations results were compared with previous results [2] using a refined grid $\left(\Delta_{r f}=0.9 \mathrm{~mm}\right)$ and different boundary conditions, such as Perfect Matched Layer - PML [8] and $1^{\text {st }}$ and $2^{\text {nd }}$ order Absorbing Boundary Conditions - ABC [9]. Good agreement between these simulations were observed.

\section{A. Patch Antenna Design}

A rectangular microstrip (patch) antenna was chosen, as a conceptual example, because its characteristics are adequate for this application, and because its design procedures are well established $[10,13]$. The cell phone with the planar antenna in its rear side is represented in Fig. 1. 

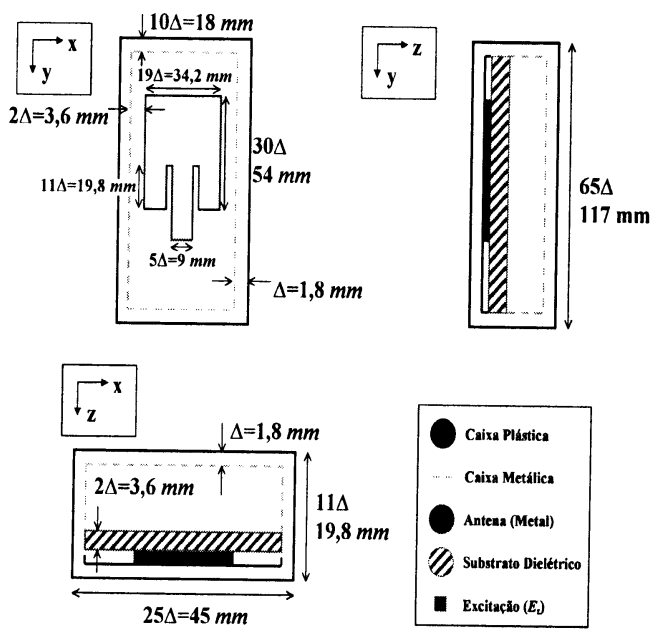

FIG. 1 - Schematic representation of the cell phone with the planar antenna fed through a transmission line.

Légende française

The substrate used in the simulations and in the developed antenna was Rogers $R T /$ Duroid ${ }^{T M} 5880$ [14] with the following parameters: $\varepsilon_{r}=2.2$, $\operatorname{tg} \delta=0.0009$, also $h=3.6 \mathrm{~mm}$ since this is multiple of the discrete unit $\Delta(\Delta=1.8 \mathrm{~mm})$. Prototypes were made with $h=1.6 \mathrm{~mm}$ and $h=3.2 \mathrm{~mm}$, which are the thickness values for the available substrates.

The transversal dimension of the antenna must be compatible with the width of the cell phone box $(45 \mathrm{~mm})$ and with the dimensions of the voxels of the grid used in the FDTD simulations $(45 \mathrm{~mm}=25 \Delta)$ [2]. With this limitation in the width, the ground plane is small, and the classical analytic methods conventionally used in the design of these antennas (as well as in some simulations) present only approximate results, and therefore measurements or more exact simulations (such as using FDTD) are needed in order to obtain an efficient characterisation.

For the antenna design, initially the antenna width is assumed equal to $W_{l}=34.2 \mathrm{~mm}$

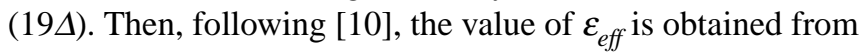

$$
\varepsilon_{e f f}=\frac{\varepsilon_{r}+1}{2}+\frac{\varepsilon_{r}-1}{2}\left(1+12 \frac{h}{W_{1}}\right)^{-1 / 2},
$$

the reduction ratio $\Delta L$ on the resonator's length: 


$$
\Delta L=0.421 h \frac{\left(\varepsilon_{e f f}+0.3\right)\left(\frac{W_{1}}{h}+0.264\right)}{\left(\varepsilon_{e f f}-0.248\right)\left(\frac{W_{1}}{h}+0.8\right)},
$$

and the length $L_{1}$ of the resonator,

$$
L_{1}=\frac{1}{2 f_{c} \sqrt{\varepsilon_{e f f}} \sqrt{\mu_{o} \varepsilon_{o}}}-2 \Delta L
$$

Therefore, if the excitation must be restricted to the dominant $T M_{010}$ mode, then $L_{1}>W_{1}>h$. Hence, when $L_{1}=54 \mathrm{~mm}(30 \Delta)$, using the equations for the cavity model [10], the resonance occurs at $1.893 \mathrm{GHz}$. In the sequence, the distance $y_{o}$ at which the excitation must penetrate in the metallisation in order to present an input impedance of $50 \mathrm{ohms}$ and therefore match it with the feeder is calculated [10],

$$
y_{o}=\operatorname{acos}\left(\frac{5}{\sqrt{R_{\text {in }}}} \sqrt{2}\right) \frac{L_{1}}{\pi},
$$

and a value of $y_{o}=19.8 \mathrm{~mm}(11 \Delta)$ is obtained.

A $50 \mathrm{ohms}$ transmission line (TL) is used, with $9.8 \mathrm{~mm}$ width and $27.7 \mathrm{~mm}$ length. In the FDTD simulations these values were respectively $9 \mathrm{~mm}$ and $27 \mathrm{~mm}$. An electric field $\boldsymbol{E}_{z}$ is imposed at the input of the TL.

This antenna has also been simulated using the software Ensemble ${ }^{T M}$ (SV v. 2.0.57) [15], and with the parameters listed above, an input VSWR of 1.014 is estimated. The calculated bandwidth [11] for VSWR $=2$ was $8 \mathrm{MHz}$, and the simulated bandwidth was around $40 \mathrm{MHz}$, as it is shown in Fig. 2, which can be compared to the measured results (Fig. 12 and 13). A reason for this difference may be the losses, which were not taken into account in the theoretical model, and surface waves associated to the complex permittivity.

This bandwidth can be further increased if a design procedure with this purpose is used. Other calculated results are the quality factors, due to: (a) conductor losses, $Q_{c}=6.61 \times 10^{3}$, (b) dielectric losses, $Q_{d}=1.205 \times 10^{3}$, (c) radiation losses, $Q_{i}=211.834$, and (d) overall quality factor, $Q_{t}=175.383$. Then, the estimated efficiency is $\eta=82.79 \%$.

It is observed that this kind of feeding is not adequate as that used in [16], in which the feeding was supplied through a coaxial probe, resulting in larger efficiency and bandwidth ( $\eta=86.17 \%$ and $B W=13 \mathrm{MHz}$ ), since here the TL contributes for the radiation, as it can be observed in the near field FDTD simulations shown in Fig. 3. 


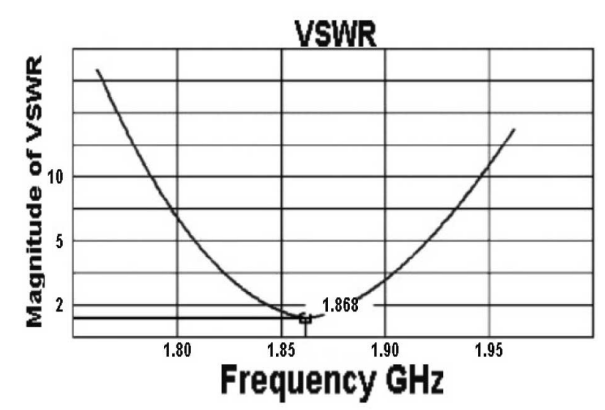

FIG. 2 - Input VSWR simulated on Ensemble $e^{T M}$ for the antenna. $L_{1}=52.2 \mathrm{~mm}$.

Légende française
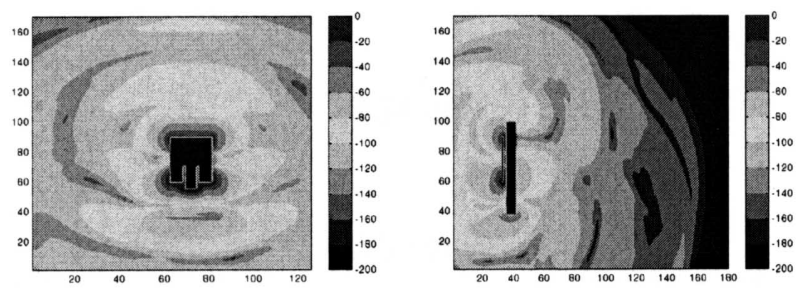

FIG. 3 - FDTD simulation of the cell phone patch antenna radiated field: frontal (left) and side (right) views.

Légende française

\section{B. Simulation of a $\lambda / 4$ Monopole Antenna}

A typical cell phone has been modelled as a metal box (ideal conductor) and a dielectric cover $\left(\varepsilon_{r}=2.1\right)$ with $1.8 \mathrm{~mm}$ thickness, having external dimensions of $45 \times 19.8 \times 117 \mathrm{~mm}$ $(25 \Delta \times 11 \Delta \times 65 \Delta)$. The $\lambda / 4$ monopole antenna was modelled as a $\lambda / 4$ metallic tube fixed on the top of the metal box, as it is shown in Fig. 4.

Since all dimensions must be multiple of $\Delta$, a central frequency of $1.8926 \mathrm{GHz}$ has been chosen, and therefore a length having $22 \Delta(39.6 \mathrm{~mm})$ corresponds to $\lambda / 4$. The antenna feeding was supplied through a coaxial cable which extends up to the boundary of the domain of calculation, where the electric field $E_{y}$ is applied (in the cell immediately below the beginning of the central conductor of the coaxial cable, see Fig. 4). In this way, the radiation from the feeding point is minimised. However, this procedure results in a propagation delay, which must be considered in the analysis of the performance. 


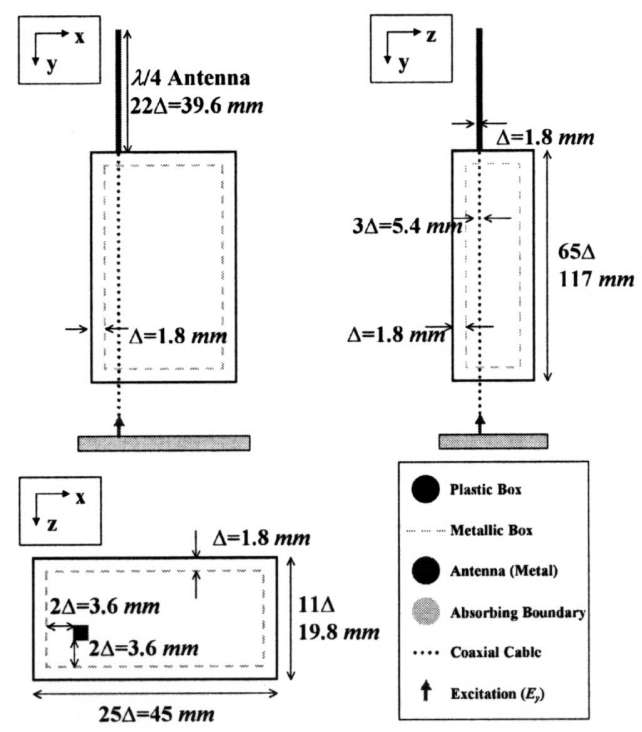

FIG. 4 - Cell phone with the $\lambda / 4$ monopole antenna fed through a coaxial cable.

Légende française

\section{Human Head Model}

The derivation of the mesh which is used for the domain of calculations based in the discretization of the human head has been described in previous paper [2]. No interpolation or smoothing were implemented to prevent staircasing. The dimensions of the head model used are shown in Fig. 5.

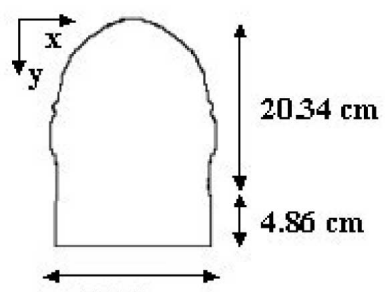

$18.72 \mathrm{~cm}$

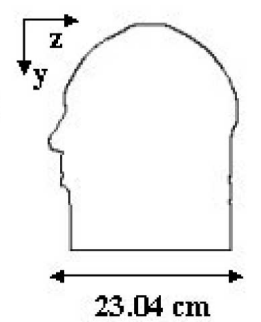

$23.04 \mathrm{~cm}$

FIG. 5 - Head model dimensions.

\section{Légende française}


In this work, the physical and electrical parameters used for the different tissues were analogous to those used by other authors $[1,2,17,19]$, in order to compare the results obtained. In Table I the parameters used at $1.9 \mathrm{GHz}$ are indicated. These values are close to those recommended by FCC [20].

TABLE I. - Properties of the Tissues used in the FDTD Simulations at Frequencies close to $1.9 \mathrm{GHz}$

\section{Légende française}

\begin{tabular}{|c|c|c|c|}
\hline Tissue & $\varepsilon_{r}$ & $\sigma[\mathrm{mho} / \mathrm{m}]$ & $\rho[\mathrm{Kg} / \mathrm{l}]$ \\
\hline Skin/Fat & 36.5 & 0.700 & 1.10 \\
Muscle & 55.3 & 2.000 & 1.04 \\
Bone & 7.75 & 0.105 & 1.85 \\
Brain & 46.0 & 1.650 & 1.03 \\
Eyes & 80.0 & 1.900 & 1.02 \\
\hline
\end{tabular}

If the hand were placed close to the antenna, it could substantially modify some radiation parameters, such as the antenna input impedance, the radiation pattern, as well as the SAR values. The exact influence of this effect would be a function of the relative position between the antenna and the hand. In [17] it has been shown that, if the hand is not placed directly over the antenna, SAR values are disturbed only a little.

\section{Near Field Simulations}

The electric field intensity $(20 \times \log |E|)$ for the two antennas are shown in Fig. 6 , on the left for the $\lambda / 4$ monopole, and on the right for the patch antenna, in frontal cut ( $x z$ plane) (at the $\lambda 4$ monopole antenna plane) and coronal cut ( $x z$ plane) (at the bottom of the $\lambda / 4$ monopole antenna), above and below, respectively. It can be observed that the fields inside the head can be substantially reduced (by more than $10 \mathrm{~dB}$ ) when the planar antenna is used. These results are in close agreement to those described in [1]. The distance between the head and the antenna is $5.4 \mathrm{~mm}$.

The SAR distribution in $\mathrm{dB}(10 \times \log [\mathrm{SAR}])$ for the same frontal and coronal cuts are shown in Fig. 7. These SAR values are normalised to an average power of $\mathrm{P}_{\text {del }}=600 \mathrm{~mW}$ delivered to the antenna, in order that $0 d B$ corresponds to a $\mathrm{SAR}=1 \mathrm{~mW} / \mathrm{g}$. Again, it can be observed that reduced SAR levels (at least $10 \mathrm{~dB}$ down ) are obtained when the patch antenna is used, if compared to the $\lambda / 4$ monopole antenna.

The maximum human exposure limit recommended by ICNIRP [21], is a SAR $=2 \mathrm{~mW} / \mathrm{g}$. This is the same as recommended by the Brazilian agency ANATEL [22]. It is observed that under the conditions of these simulations, when the monopole antenna is used, the SAR in the head can be several times above the $2 \mathrm{~mW} / \mathrm{g}$ limit. This is in very close agreement to the results described elsewhere [1, 17-19]. However, as it has been shown in previous paper [2], 


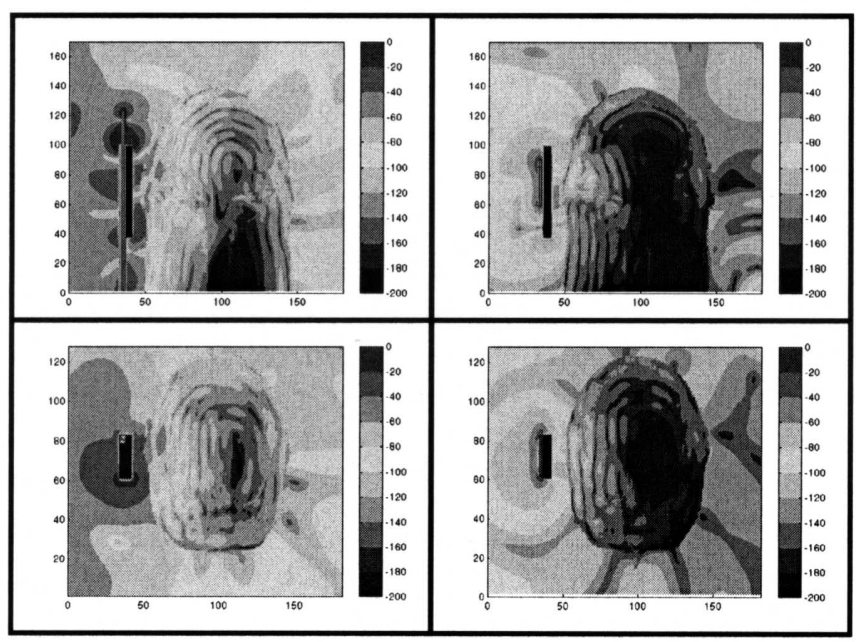

FIG. 6 - Frontal ( $x y$ plane) and coronal ( $x z$ plane) images showing the electric field intensity $(20 \times \log |E|)$ obtained at the end of the simulations

Left: $\lambda / 4$ monopole and right: microstrip patch antenna.

Légende française

if the antenna were operated at a distance sufficiently apart from the user's head (e.g. $\mathrm{d} \geq 2.5 \mathrm{~cm}$ from the head), then the SAR in the head would be below the ICNIRP limit of $2 \mathrm{~mW} / g$. The patch antenna simulations show that the field intensity and the SAR in the head are substantially reduced, to levels in accordance with ICNIRP limits. Similar results obtained for other planar antennas were reported elsewhere [1, 17-19].

It is not the intention of this paper to discuss and compare the results obtained for the SAR values when different spatial average (e.g., averages in a volume corresponding to $10 \mathrm{~g}$ or $1 \mathrm{~g}$ of tissue) or punctual values are taken into account. One of the main purposes of this paper is to compare the relative specific absorption rates when monopole and planar antennas are used, showing a reduction in the SAR when planar antennas are used. This is true even when spatial average or punctual SAR values are taken into account.

In order to calculate the radiation efficiency, the power absorbed in the user's head is added to the antenna losses and this is named overall absorbed power $\mathrm{P}_{\mathrm{abs}}$. Since the power absorbed in the user's head is reduced when the planar antennas are used, then an increase on the radiation efficiency $\eta=\left(\mathrm{P}_{\mathrm{del}}-\mathrm{P}_{\mathrm{abs}}\right) / \mathrm{P}_{\mathrm{del}}$ is obtained, as compared to the use of $\lambda / 4$ monopole antennas. This has been discussed earlier [1]. 

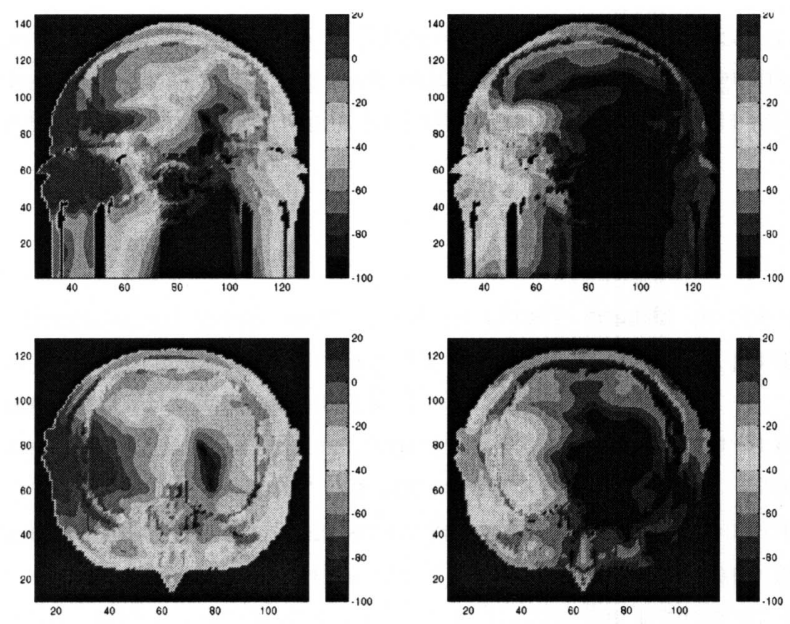

FIG. 7 - Frontal ( $x y$ plane) and coronal ( $x z$ plane) images showing the SAR distribution $(10 \times \log |E|)$ obtained at the end of the simulations

Left: $\lambda / 4$ monopole and right: microstrip patch antenna.

Légende française

\section{A. The FDTD Method with a Multidimensional Mesh}

When an exact representation of the non-homogeneous structure of the head tissues and of the detailed structure of the antenna are required, a mesh (or grid) with small dimension cells is necessary. Starting from available neuro-anatomical data base [23], a model for the human head including cells with $\Delta=1.8 \mathrm{~mm}$ [2] has been generated, and this is the "thin mesh". However, to extend the simulation to the far field region where the radiation pattern is calculated, and in order to save memory and processing time, the domain includes a "thick mesh" [18, 24-25], in which the cells have $\Delta_{g}=27 \mathrm{~mm}$. A representation of the domain composed by a bi- dimensional mesh is shown in Fig. 8. Since $\Delta_{g}$ is 15 times greater than $\Delta$, then

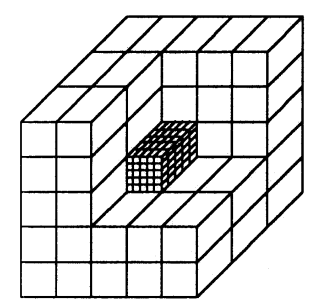

FIG. 8 - A bi-dimensional mesh.

Légende française 
the calculations to update the field values in the thick mesh will occur only after 15 iterations in the thin mesh region.

The dimensions in the thin mesh region are $23.04 \times 30.60 \times 32.40 \mathrm{~cm}^{3},(128 \Delta \times 170 \Delta \times$ $180 \Delta)$, and in the thick mesh region are $3.51 \times 3.645 \times 4.59 \mathrm{~m}^{3}\left(130 \Delta_{g} \times 135 \Delta_{g} \times 170 \Delta_{g}\right)$. As mentioned in the beginning of this section, an absorbing wall as described by Mur (second order) was used as boundary condition [9]. In previous work we used Bérenger PML [8] with different number of cells (up to 32 cells) showing return loss as low as $-80 \mathrm{~dB}$. Since reflected waves do not contribute to change significantly the SAR values in the critical regions, we then used Mur ABC. This saves memory and processing time, and the difference in SAR or radiation patterns is a few percent, as it is shown in [26].

\section{B. Far Field Simulations}

FDTD simulations with bi-dimensional mesh were used to obtain results in the far field region $(d \geq 10 \lambda)$ at frequencies around $1.9 \mathrm{GHz}$. The simulations stability in the coarse mesh is guaranteed by Courant condition. Convergence and dispersion issues were discussed in [18, 27-32].

The number of points per wavelength used at the present work for the coarse mesh is close to $6\left(N_{\lambda}=\Delta_{g} / \lambda=5,85\right)$. As it is shown in [27], the convergence error for the coarse mesh (filled with homogeneous media, e.g. the free space) with $N_{\lambda} \approx 6$, is equivalent to the convergence error for a non-homogeneous media with $N_{\lambda} \approx 30$ (for the thin mesh we used $N_{\lambda} \approx 90$ ). Also in [28] it was shown that for $N_{\lambda} \approx 6$, numerical dispersion (attenuation and phase) for homogeneous waves is negligible and convergence will be achieved for a number of points per wavelength even lower than the Nyquist rate (i.e. $N_{\lambda}<2$ ).

In order to test the far field simulations, a dipole radiation pattern was modelled. Maximum differences of around $1 \mathrm{~dB}$ were observed for the horizontal pattern. Attenuation at diagonal directions (with respect to the mesh) were lower than those at normal directions, in accordance with [28].

Simulations were performed with and without the presence of the head, both using the planar and the conventional monopole antenna. The resulting horizontal plane radiation patterns in polar form are shown in Figs. 9 and 10, in which the radial scale is $5 d B$. In order to facilitate the comparisons, these radiation patterns are normalised to the value radiated in the direction opposed to the head.

The horizontal plane radiation pattern for the $\lambda / 4$ monopole antenna in the presence of the head (dotted line) is compared in Fig. 9, using similar simulation procedures, with the radiation pattern obtained for this antenna when the head is absent (continuous line). A reduction of around $5 d B$ in the direction of the head is observed. This is in close agreement with the "Body Loss" margin recommended by some authors when cell phone link path losses are considered [33, 34].

The horizontal plane radiation patterns in the absence (left) and in the presence (right) of the head are shown in Fig. 10, for the planar antenna (dotted line) and for the monopole antenna (continuous line). A front to back ratio of around $10 \mathrm{~dB}$ is observed for the planar antenna. 


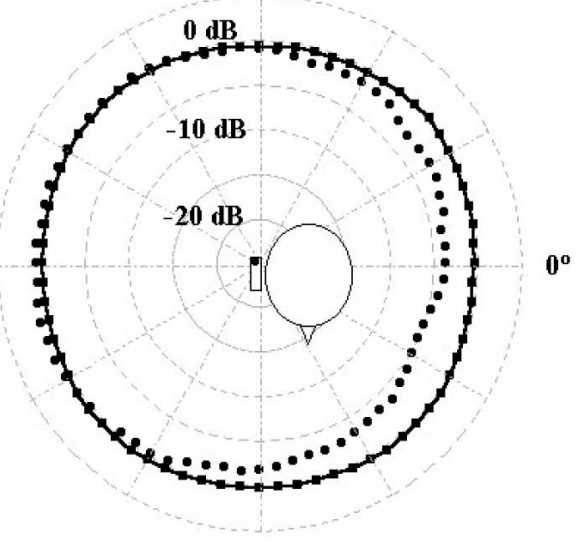

FIG. 9 - Radiation pattern (horizontal plane) for the $\lambda / 4$ monopole antenna: without the head (continuous line) and including the head (dotted line).

\section{Légende française}

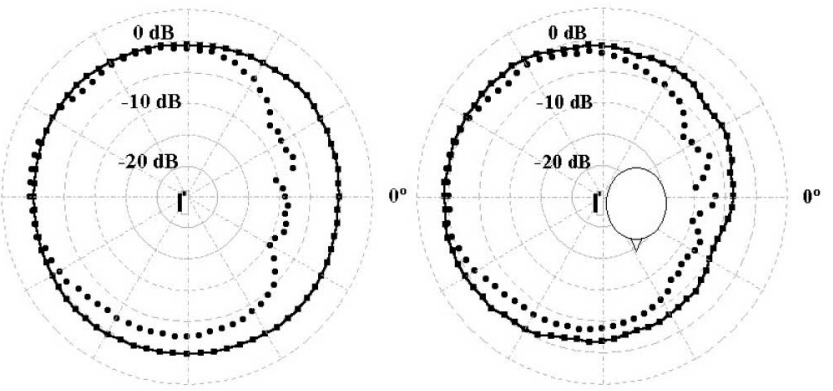

FIG. 10 - Horizontal plane radiation pattern without (left) and with (right) the head: monopole antenna (continuous line) and planar antenna (dotted line).

\section{Légende française}

Therefore, if this antenna is made with small loss substrate and if it is designed to present a small input VSWR in the desired bandwidth, then the energy radiated in the direction opposed to the head (which is the desired direction for communication) is improved, in comparison to the conventional monopole antenna. Hence, an improvement in the quality of communication and in the link performance is expected, as well as a reduction in the battery drain. 


\section{MEASURED RESULTS}

Two experimental prototypes of the designed antenna were developed on $1.8 \mathrm{~mm}$ thickness RT/duroid $^{T M} 5880$ substrate and using SMA connectors (Fig. 11).

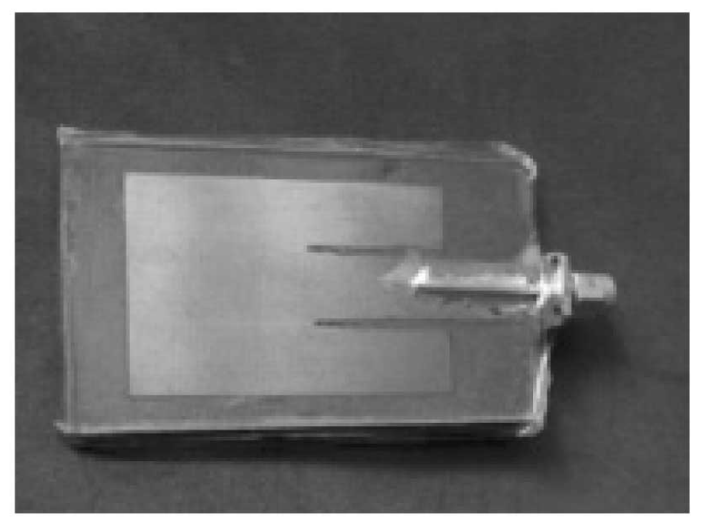

FIG. 11 - One of the patch antennas developed and measured.

Légende française

Measurements using model S331A Wiltron and model MS2711 Anritsu spectrum analysers show a frequency of resonance slightly above that expected, and a bandwidth around 5 $\%$ when VswR is $<2$, as it is shown in Fig. 12. Further prototypes are being tested in order to correct this.

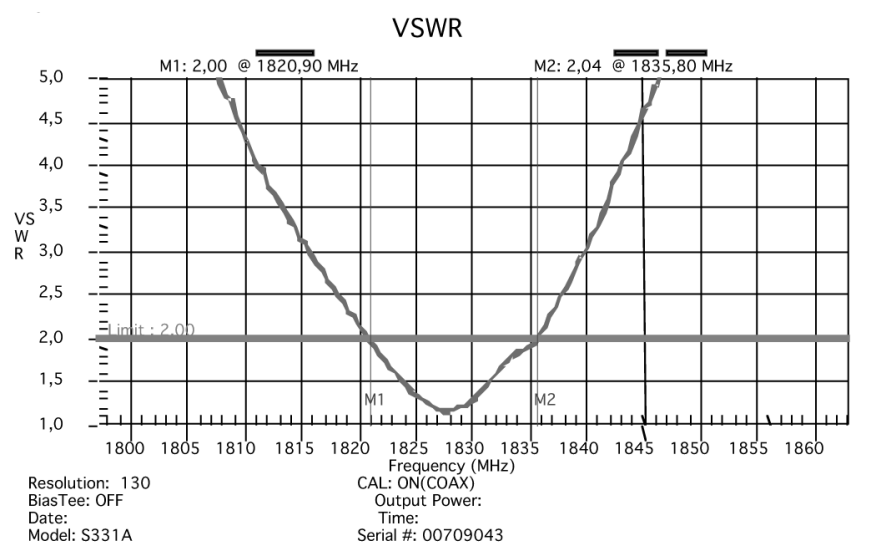

FIG. 12 - Standing Wave Ratio measured with Wiltron S331A.

Légende française 
Measurements were then performed in a $5 \times 5 \times 5 \mathrm{~m}^{3}$ anechoic chamber, in which the receiver was a Electro-Metrics $E M C-60$ super-heterodyne interference analyser, coupled to the antenna under test, the generator was a Wiltron $6745 B$ frequency synthetizer, coupled with a Varian VZL6041-K1 amplifier, and a standard horn antenna.

Using this, two sets of measurements where performed: (a) in one set of measurements, the ground plane of the patch antenna was not connected to the ground mesh of the receiver cable, in order to simulate the usual operational situation with cell phones (e. g., without effective ground plane); and (b) measurements with the connector bonded to the ground plane. The antenna gain variation on the frequency band from 1.840 to $1.930 \mathrm{MHz}$ shown in Fig. 13 was measured for this last configuration. This is more in accordance with calculations using the cavity model than the measurements without effective ground plane shown in Fig. 12.

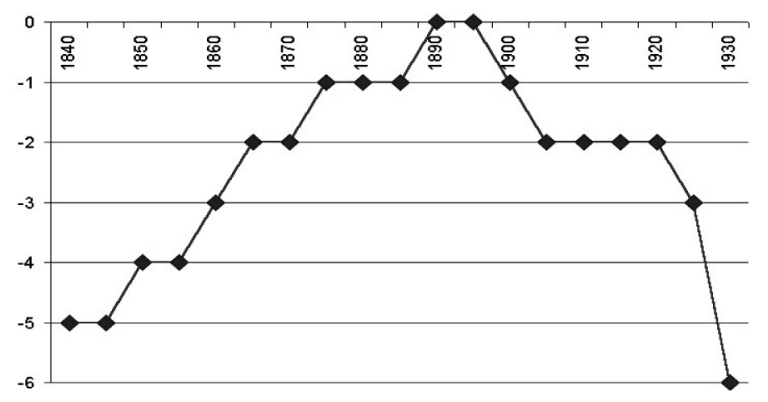

FIG. 13 - Patch antenna gain variation (in $d B$ ) in function of the frequency (in $\mathrm{MHz}$ ) as measured with the EMC-60.

Légende française

Fig. 14 shows the vertical and horizontal plane radiation patterns when measured without effective ground plane.
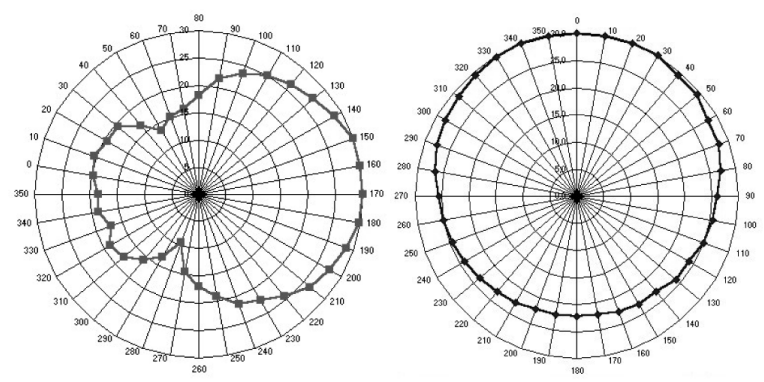

FIG. 14 - Vertical plane (left) and horizontal plane (right) radiation pattern as measured for the patch antenna without effective ground plane (radial scale: $5 \mathrm{~dB}$ per division).

\section{Légende française}


Fig. 15 shows the horizontal plane radiation pattern measured for the patch antenna with effective ground plane.

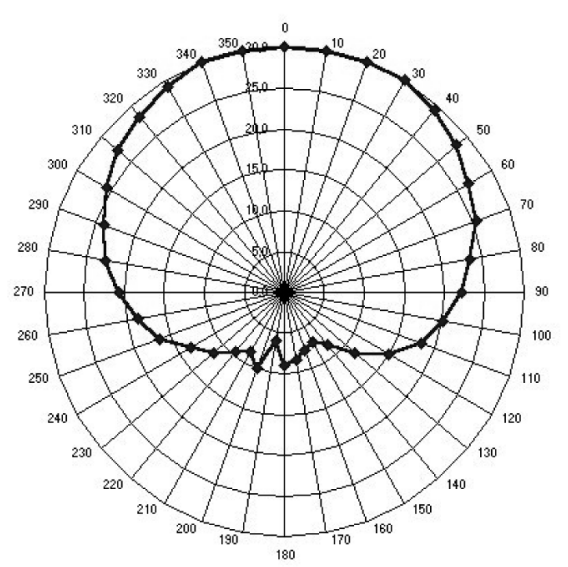

FIG. 15 - Horizontal plane radiation pattern as measured for the patch antenna with effective ground plane (radial scale: $5 \mathrm{~dB}$ per division).

Légende française

It is observed that when the ground plane is not effectively grounded, a front to back ratio of around $10 \mathrm{~dB}$ and a $3 \mathrm{~dB}$ beamwidth of around $150^{\circ}$ are measured. These values are in close agreement to those obtained using the FDTD simulations [2]. However, when the ground plane is effectively grounded, a front to back ratio greater than $20 \mathrm{~dB}$ and a half power beamwidth of $110^{\circ}$ are measured.

Fig. 16 shows a tri-dimensional representation of the fields radiated from the patch antenna with effective ground plane.

Fig. 17 shows the horizontal plane radiation patterns measured for the patch antenna with and without effective ground plane and that obtained using FDTD simulations.

These results may be adequate for applications on many mobile phones. Also, it is expected that improved results (e. g., in terms of bandwidth, vswR, radiation efficiency, front to back ratio, etc...) can be achieved using other types of planar antennas with optimized design $[1,3,35-36]$.

It can be observed, that there is an additional advantage when the FDTD method is used, as compared to other numerical, analytical or hybrids methods. This is because in the FDTD method the simulation of the planar antenna does not require the assumption of an infinite and ideal ground plane. As a consequence of that, a more realistic situation is simulated, and then the obtained results must be more exact. 


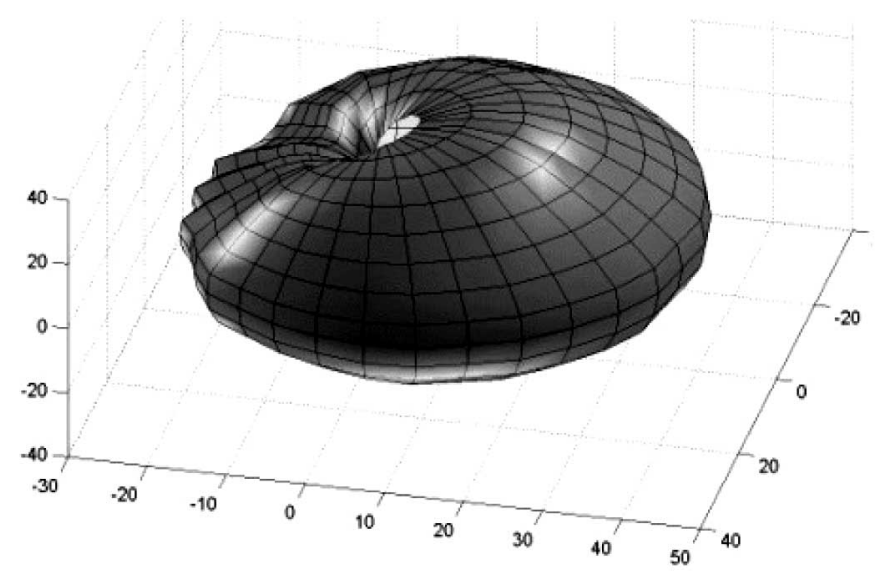

FIG. 16 - Tri-dimensional representation of the patch antenna radiation pattern.

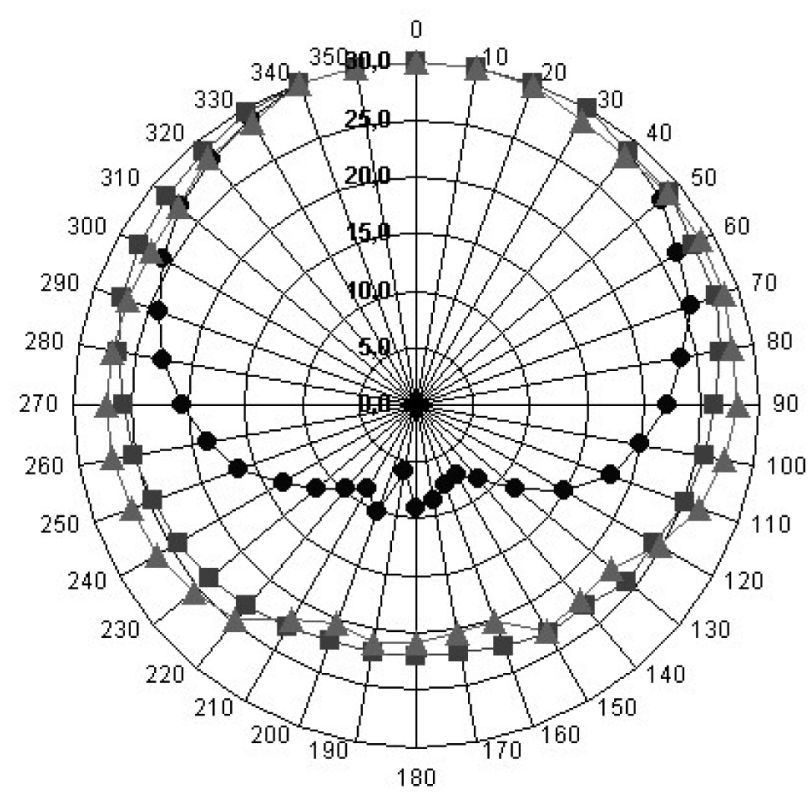

FIG. 17 - Horizontal plane radiation pattern measured for the patch antenna when ground plane was effectively grounded $[\bullet]$, without effective ground $[\square]$ and calculated using FDTD simulations [ $\mathbf{\Lambda}]$ (radial scale: $5 d B$ per division).

\section{Légende française}




\section{COMMENTS AND CONCLUSIONS}

The design, simulation and measured results of a $1.9 \mathrm{GHz}$ microstrip rectangular patch antenna were presented. The software Ensemble ${ }^{T M}$ was used to simulate the input VswR and the bandwidth. The FDTD method was used to estimate the radiation pattern, the fields in the near region as well as the SAR in the user's head. It is observed that when there is not an effective grounding at the ground plane (and this is the typical operational situation for the cell phones), the radiation pattern measurements are in very close agreement with the simulations using the FDTD method. The measured bandwidth was around $5 \%$, which can be adequate in several practical applications. Other estimated and measured characteristics, such as the input VSWR (smaller than 2) and the radiation efficiency (around $80 \%$ ) can also be adequate for applications in mobile phones. A front to back ratio of the order of $10 \mathrm{~dB}$ and a $3 \mathrm{~dB}$ beamwidth around $150^{\circ}$ were also obtained. These lead to a reduction of the SAR in the head to levels that can be below the exposure limits established by the available standards $[21,22]$. It is very important to remark that when the conventional monopole antenna is used, the SAR can reach levels substantially above the limit of SAR $=2 \mathrm{~mW} / \mathrm{g}$ established at ICNIRP guidelines [21] in some regions of the user's head.

As the exposure limits were established only considering the thermal effects of the non ionizing radiation, there is a considerable possibility that these limits become substantially lower if the non thermal effects of the non ionizing radiation turn to be formally acknowledged by some organizations such as WHO - World Health Organization, ICNIRP/CENELEC, IEEE/ANSI, etc. Among others, there is a great concern related to the long-term effects of continuous low level exposures. Also, other effects not considered in this work, such as pulsed radiation, may produce low-level non-thermal effects in some sensitive brain cells and membranes, requiring therefore careful investigations.

The planar antennas, showing small input VSwR, high radiation efficiency and moderate directivity, with small dimensions, compact, being able to be integrated in the cell phone box and with low production costs, may represent an important and desired choice for future generations of mobile phones. This would improve the quality of communication, reduce the battery drain and the users health risks.

Finally, the new generation of cellular phones (e.g. $2.5 \mathrm{G}$ and $3 \mathrm{G}$ ) including services of message, voice, data, video, etc., will transmit higher data rates and may require higher transmitted power. This would result in greater risk for the cellular phone user unless directive antennas were employed.

Manuscrit reçu le 27 novembre 2003

Accepté le 25 mars 2004

\section{Acknowledgment}

The authors are grateful to Eng. Leandro N. de Souza and Sérgio L. Prass, from CIENTEC - RS, Eng. Luis Hélio M. Teles from ALR Sistemas Digitais, to Prof. Jorge A. Lisbôa, Eng. 
Paulo I. Serafini, to Rudolf Gnewuch, Gabriel F. Lamas and Ernani Poletto, for their important assistance during the measurements and different activities of this project.

\section{REFERENCES}

[1] Jensen (M. A.), Rahmat-SAmi (Y.), "EM Interaction of Handset Antennas and a Human in Personal Communications", Proc. of the IEEE, 83, no 1, pp. 7-17, January 1995.

[2] De Salles (A. A.), Fernández (C. R.), Bonadiman (M.), "Far Field, Near Field and sar Simulation for Cell Phones Operating Close to the Head" IEEE - COMSOC International Telecommunications Symposium (ITS2002), Natal - RN, September 2002.

[3] Rowley (J. T.), Waterhouse (R. B.), "Performance of Shorted Microstrip Patch Antennas for Mobile Communications Handsets at 1800 MHz", IEEE Trans. Antennas Propagat., 47, nº 5, pp. 815-822, May 1999.

[4] DeAl (W. R.), Qian (Y.), Itoh (T.), "Planar Integrated Antenna Technology”, Microwave Journal, pp.128-144, July 1999.

[5] SAnad (M.), Amant (N. H.), "An Internal Integrated Microstrip Antenna for PCs/Cellular Telephones and other Hand-held Portable Communication Equipment", Microwave Journal, pp.64-77, July 1998.

[6] Centro Nacional de Supercomputação - CESUP/RS. Available from World Wide Web: http://www.cesup.ufrgs.br

[7] Taflove (A.), Computational Electrodynamics- the Finite Diference Time Domain Method, Artech House 1995, ISBN 0-89006-792-9

[8] Bérenger (J. P.), "A perfect matched Layer for Absorption of Electromagnetic Waves", Journal of Computational Physics, 114, pp.185-200, 1994.

[9] Mur (G.), "Absorbing Boundary condition for the Finite-Difference Approximation of the Time-Domain Electromagnetic-Field Equations" IEEE Trans. Electromagnetic Compatibility, 23, pp. 377-382, November 1981.

[10] Garg (R.), Bhartia (P.), Bahl (I.), Ittipiboon (A.), Microstrip Antenna Design Handbook. Artech House 2001, ISBN 0-89006-513-6

[11] Balanis (C. A.), Antenna Theory: Analysis and Design. John Wiley \& Sons, 1997, isBn 0-471-59268-4, ch.14.

[12] Bhartia (P.), Rao (K. V. S.), Tomar (R. S.), Millimeter-Wave Microstrip and Printed Circuit Antennas. Artech House 1991, ISBN 0-89006-333-8

[13] James (J. R.), Hall (P. S.), Wood (C.), Microstrip Antenna Theory and Design. Peter Peregrinus 1981, ISBN $0-906048-57-5$

[14] RT Duroid ${ }^{\text {TM }}$ datasheet Available from World Wide Web: http://www.rogerscorporation.com/acm/index.htm

[15] Ansoft Designer. Available from World Wide Web: http://www.ansoft.com

[16] De Salles (A. A.), Fernández (C.), Bonadiman (M.), "Simulação do Campo Distante e da SAR na Cabeça do Usuário do Telefone Celular para Antenas Convencionais e Planares" X Simpósio Brasileiro de Microondas e Optoeletrônica, Recife - PE, Agosto 2002.

[17] Watanabe (S.) et al., "Characteristics of the SAR Distributions in a Head Exposed to Electromagnetic Fields Radiated by a Hand-Held Portable Radio", IEEE Trans Microwaves Theory Techniques, 44, n. 10, pp. 18741883, October 1996.

[18] IsKander (M. F.) et al., "Polarization and Human Body Effects on the Microwave Absorption in a Human Head Exposed to Radiation from Hand Held Devices", IEEE T-MTT, 48, nº. 11, pp. 1979-1987, November 2000.

[19] Bernardi (P.) et al., "Power Absorption and Temperature Elevation Induced in the Human Head by a DualBand Monopole-Helix Antenna Phone", IEEE T-MTT, 49, nº. 12, pp. 2539-2546, December 2001.

[20] Federal Communications Commission: Tissue Dielectric Properties Available from World Wide Web: http://www.fcc.gov/fcc-bin/dielec.sh

[21] ICNIRP Guidelines, "Guidelines for Limiting Exposure to Time-Varying Electric, Magnetic and Electromagnetic Fields (Up to $300 \mathrm{GHz}$ ), International Commission on Non-Ionizing Radiation Protection", Health Physics, 74, nº. 4, pp. 494-522, April 1998.

[22] ANATEL, Regulamento sobre Limitação da Exposição a Campos Elétricos, Magnéticos e Eletromagnéticos na faixa de Radiofreqüências entre $9 \mathrm{kHz}$ e $300 \mathrm{GHz}$, anexo à Resolução nº 303 de 2 de Julho de 2002.

[23] National Library of Medicine - Center for Biomedical Informatics, Unicamp: The Visible Human Project ${ }^{\mathrm{TM}}$ South America Mirror. Available from World Wide Web: 〈http://www.vhd.org.br〉.

[24] OKоniewski (М.), Oкоniewska (Е.), Stuchly (М. А.) "Three-Dimensional Subgridding Algorithm for FDTD” IEEE Trans. Antennas Propagat., 45, nº. 3, pp. 422-429, March 1997. 
[25] White (M. J.), Yun (Z.), IsKANDER (M. F.), “A New 3-D FDTD Multigrid Technique with Dielectric Transverse Capabilities", IEEE Trans. Microwave Theory and Techniques., 49, nº 3, pp. 422-430, March 2001.

[26] Lazzi (G.), Furse (C. M.), Gandhi (O. P.), "Optimization and Design Conductivity Profiles for the PML Boundary Condition and Its Application to Bioelectromagnetic Problems", IEEE - APS International Symposium - 1997 Digest, 1, pp. 486-489, ISBN 0-7803-4178-3, Montreal - Canada, 13-18 July 1997.

[27] Menezes (L. R .A. X.), Hoefer (W. J. R.), “Accuracy of tLm Solutions of Maxwell's Equations”, IEeE Trans. Microwave Theory and Techniques., 44, n. 12, pp. 2512-2518, December 1996.

[28] Schneider (J. B.), Kruhlak (R. J.), "Dispersion of Homogeneous and Inhomogeneous Waves in the Yee Finite-Difference Time-Domain Grid”, IEEE Trans. Microwave Theory and Techniques., 49, nº. 2, pp. 280-287, February 2001.

[29] Nehrbass (J. W.), Jevtic (J. O.), LeE (R.), "Reducing the Phase Error for Finite-Difference Methods Without Increasing the Order", IEEE Trans. Antennas Propagat., 46, no 8, pp. 1194-1201, August 1998.

[30] Chung (Y-S.), Sarkar (T. K.), Jung (B. H.), Salazar-Palma (M.), "An Unconditionally Stable Scheme for the Finite-Difference Time-Domain Method" IEEE Trans. Microwave Theory and Techniques., 51, nº. 3, pp. 697-704, March 2003.

[31] Teixeira (F. L.), Hwang (K-P.), Chew (C. W.), Jin (J-M.), "Conformal PML-FDTD Schemes for Electromagnetic field simulations: A Dynamic Stability Study” IEEE Trans. Antennas Propagat., 49, nº 6, pp. 902-907, June 2001.

[32] Dridi (K. H.), Hesthaven (J. S.), Ditkowski (A.), "Staircase-Free Finite-Difference Time-Domain Formulation for General Materials in Complex Geometries" IEEE Trans. Antennas Propagat., 49, no 5, pp. 749756, May 2000.

[33] Holma (H.), Toskala (A.), wCDma for umts: Radio Access for Third Generation Mobile Communications. John Wiley \& Sons, 2001, ISBN 0-471486-87-6, ch. 8.

[34] Nielsen (J.) et al., "Statistics of Measured Body Loss for Mobile Phones", IEEe Trans. Antennas Propagat., 49, no. 9, pp. 1351-1353, September 2001.

[35] Neves (E. S.), Lacava (J. C.), Cividanes (L.), "Dual band Rectangular Patch Antenna with Two Pairs of Parallel Slits", IEEE - APS International Symposium on AP (APS2002), 2, pp. 52-55.

[36] Garg (R.), Reddy (V. S.), "A Broad-Band Coupled-Strips Microstrip Antenna”, IEEE Trans. Antennas Propagat., 49, nº. 9, pp. 1344-1345, September 2001. 